\title{
Analgesia for total knee arthroplasty using continuous femoral nerve block: comparison between two rates of drug infusion using $0.125 \%$ levobupivacaine.
}

Montagud A. ${ }^{1}$, Rodriguez P. ${ }^{2}$, Gómez L. ${ }^{3}$, Hernandez M.J. , , Moliner S. , De Andrés J. ${ }^{4}$

Hospital Consorcio Universitario General de Valencia, Dept of Anaesthesiology and Pain Medicine, Valencia

\section{BACKGROUND}

Total knee arthroplasty ( TKA ) is associated to severe postoperative pain. For its control, continuous femoral nerve block ( CFNB ) analgesia has proven as a successful technique, but the prope infusion rate is controversial.

Our goal is to evaluate effiiciency and safety ot two infusion rates of $0,125 \%$ levobupivacaine through a CFNB after TKA

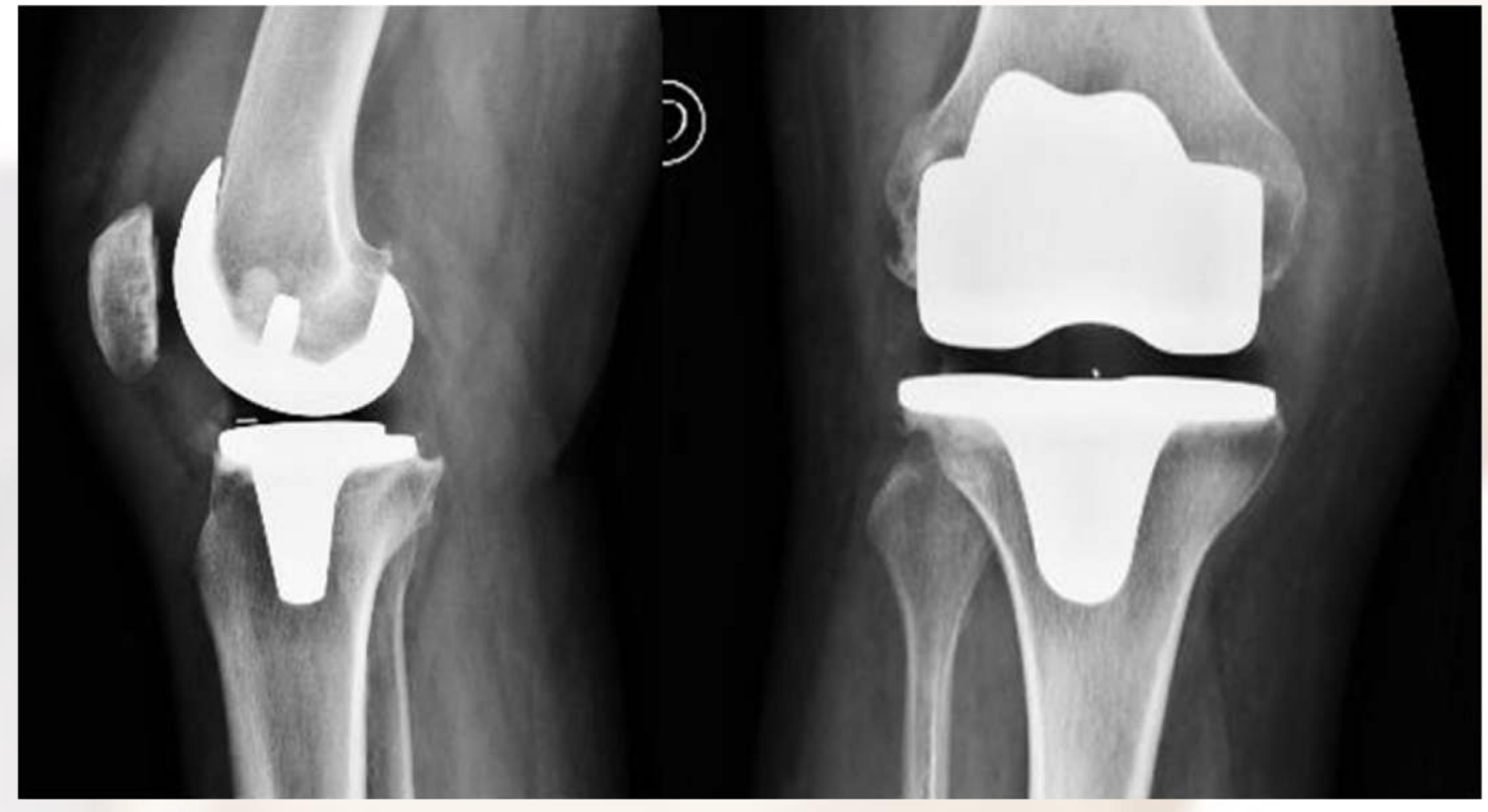

\section{MATERIAL AND METHODS}

Comparative and retrospective study of 382 patients scheduled to TKA. with postoperative analgesia using CFNB between 2014 and 2015. Patients are divided in two groups, depending on the infusion rate with $0,125 \%$ levobupivacaine: $7 \mathrm{ml} / \mathrm{h}$ or $12 \mathrm{ml} / \mathrm{h}$. For both groups, complementary analgesia was conducted with paracetamol and dexketoprofen and first rescue analgesics was tramadol. Demographic characteristics, VAS $(\mathrm{mm})$ scores at rest and in motion after $24 \mathrm{~h}$, dispensed boluses and complications were recorded

\section{RESULTS}

382 patients were included, 245 in the $7 \mathrm{ml} / \mathrm{h}$ infusion rate group and 137 in the $12 \mathrm{mlh}$ one. No demographic differences were found among bothgroups. The group of $12 \mathrm{ml} / \mathrm{h}$ registered slightly lower VAS medium levels than the $7 \mathrm{ml} / \mathrm{h}$ group after $24 \mathrm{~h}$, being statistically not significant $(p<0,05)($ table 1 ). Patients that received an infusion rate of 7 $\mathrm{ml} / \mathrm{h}$ need a higher amount of boluses than those of $12 \mathrm{ml} / \mathrm{h}$ group ( 5 or more boluses: $45,1 \%$ in $7 \mathrm{ml} / \mathrm{h}$ group vs. $39 \%$ in the $12 \mathrm{ml} / \mathrm{h}$ group ). All the complications recorded are shown in table 2 . The best choice of local anesthesic, including concentration and optimal volume, is controversial. Infusion rates under $4.6 \mathrm{ml} / \mathrm{h}$ for CFNB have been provn to be inefficient, but the use of higher rates has not yet been sufficiently studied.

\begin{tabular}{|l|l|l|}
\hline VAS $24 h$ & At rest $(\mathrm{mm})$ & In motion $(\mathrm{mm})$ \\
\hline Group $7 \mathrm{ml} / \mathrm{h}$ & $26,2($ SD 21,8) & $32,2($ SD 29,9) \\
\hline Group $12 \mathrm{ml} / \mathrm{h}$ & $24,8($ SD 19,6) & $32,1($ SD 22,2) \\
\hline
\end{tabular}

TABLE 1

\begin{tabular}{|l|l|l|}
\hline COMPLICATIONS & Group $7 \mathrm{ml} / \mathrm{h}$ & Group $12 \mathrm{ml} / \mathrm{h}$ \\
\hline $\begin{array}{c}\text { Nausea/vomits } \\
(\mathrm{p}<005)\end{array}$ & $14,6 \%$ & $5,1 \%$ \\
\hline Motor block & $0,8 \%$ & $0,7 \%$ \\
\hline Paresthesia & $4 \%$ & $4,3 \%$ \\
\hline Catheter released & $9,7 \%$ & $8 \%$ \\
\hline
\end{tabular}

TABLE 2

\section{CONCLUSIONS}

Using of high infusion rates $(12 \mathrm{ml} / \mathrm{h}$ ) of $0,125 \%$ levobup. Through a CFNB delivers a similar analgesia in comparison to moderate rates $(7 \mathrm{ml} / \mathrm{h})$ without increasing complications. However, a high infusion rate seems to decrease. The necessity of rescue analgesia and thus the resulting complications due to opioids consumption. 